\title{
A missão da rede memorial: capital social, sistemas e redes de colaboratividade
}

\author{
Mário Gouveia Júnior \\ Doutorando; Universidade do Porto e Universidade de Aveiro (UP e UA); \\ gouveia_historiador@yahoo.com.br \\ Marcos Galindo \\ Doutor; Universidade Federal de Pernambuco (UFPE); \\ galyndo@gmail.com \\ Sandra Maria Verissimo Soares \\ Mestre; Arquivo Público Jordão Emerenciano (APEJE); \\ sandra.verissimo9@gmail.com \\ Ângela Cristina Moreira do Nascimento \\ Mestre; Superintendência de Desenvolvimento do Nordeste (SUDENE); \\ angela.cmn@gmail.com
}

\begin{abstract}
Resumo: Este texto debate a importância da formação e consolidação de uma rede de instituições de missão memorial em prol da preservação de informação, de sua disseminação e do seu franco e irrestrito acesso. Ilustram nossas considerações a ideia de sistema memorial, pensada enquanto categoria de trabalho que preza pela protocooperação e pelo compartilhamento de informação. Contemplamos a perspectiva de que, trabalhando em conjunto, as instituições podem contribuir de modo mais eficaz no tocante ao compartilhamento de conteúdos informacionais. Da mesma forma, ainda abordamos a formação da Rede Memorial - a busca por uma integração nacional que teve por base uma carta de princípios para sustentar uma política de preservação e acesso aos acervos memoriais e de procedimentos para a conformação de um espaço colaborativo de trabalho.
\end{abstract}

Palavras-chave: Sistemas memoriais. Rede memorial. Colaboratividade. Acesso à informação.

\section{Introdução}

Segundo especialistas de vários campos do conhecimento, a linguagem se tornou necessária quando os primeiros homens iniciaram relações de cooperação e intencionalidade de comunicação e compartilhamento de informação. Quando esses grupos humanos se tornaram hábeis em conceber e manipular ferramentas extensoras de suas limitadas capacidades e associaram tais competências ao domínio 
da linguagem, alcançaram maiores chances de subsistência frente às ainda adversas condições do meio (GALINDO; MIRANDA; BORBA, 2011). Ademais, a familiarização com as habilidades de entender e de se fazer entender contribuíram sobremaneira para a disseminação do conhecimento existente, que, por sua vez, engendrou cada vez maiores possibilidades de se aprender com experiências do outro e aprimorar noções e expectativas (GOUVEIA JUNIOR; GALINDO, 2012).

A memória dos grupos humanos e suas produções intelectuais abrigaram-se na oralidade, contando com a inteligência daqueles que fossem capazes de se expressar através da fala. Todavia, quanto mais o volume de informações a serem armazenadas crescia, mais essa capacidade se tornava a prerrogativa de poucos; os homens-memória registravam os eventos contemporâneos com a mesma habilidade com que recordavam à comunidade os eventos passados (GOUVEIA JUNIOR, 2012). E tal função, naturalmente geradora de distinção, era devidamente transmitida a outro elemento daquele grupo antes da morte do sábio.

A partir do momento em que a quantidade de informação acumulada tornouse significativa, cada morte, por exemplo, de um velho griot - categoria de contadores de histórias que viviam em várias partes da África - representava a perda de muita informação (GOUVEIA JUNIOR, 2014), sendo mais do que válido o provérbio indo-africano: "Quando morre um velho, arde uma biblioteca". Nesse particular, o costume de manter o conhecimento como prerrogativa inerente à ordem do sagrado foi legado às sociedades ocidentais. Nessa perspectiva, a curadoria do conhecimento ainda tem sido considerada por muitos como uma espécie de sacerdócio. Funções religiosas e de poder estiveram, desde há muito, atreladas às figuras daqueles que dominavam o conhecimento. Em contrapartida, no universo laico estavam os homens comuns sem acesso aos códigos escritos (GALINDO, 2012a).

Com o advento da escrita e, sobretudo, com as inovações tecnológicas que permitiram a invenção e a posterior popularização da imprensa, as pessoas passaram a comunicar ideias através de signos visuais e a produzir um registro perene destes, criando, assim, uma memória exterior à mente (GOUVEIA JUNIOR, 2012). As memórias de papel e as necessidades por lugares de memória (NORA, 1993) 
detentores de documentos e monumentos históricos e culturais dilatavam-se à medida que se complexificavam as sociedades e suas relações.

Arquivos, bibliotecas, museus e centros de documentação surgiram como formas de se acumular testemunhos materiais dos grupos humanos, movidos pelo sonho de armazenar em tais suportes o conhecimento produzido e, em tese, torná-los passíveis de recuperação. Entretanto, em muitos lugares, durante muito tempo, a lógica do acesso à informação se configurava como uma espécie de privilégio concedido a poucos. Em prol da preservação e da conservação, a maioria das pessoas estava excluída dessa lógica custodialista. Até porque deixar que documentos caíssem nas mãos de qualquer um assombrava os guardiões da memória e da informação (SILVA; RIBEIRO, 2011).

Esse estado de coisas tem-se transformado à medida que os gestores e os indivíduos que compõem as instituições de missão memorial assumem o entendimento e o compromisso de que a sua função e o seu valor social estão alocados em práticas de disseminação e compartilhamento de informação. Busca-se, desse modo, e cada vez mais, superar as práticas de salvaguarda e retenção de conteúdos informacionais. Outro entendimento importante é o de atuação conjunta, isto é, o desenvolvimento de trabalhos que integram e incentivam instituições distintas, que se aproximam e conseguem benefícios mútuos. É justamente acerca dessas relações de colaboração e trabalho integrado que trataremos neste artigo.

Na primeira parte deste trabalho é abordada a ideia de Sistemas Memoriais como categoria de trabalho que preza pela protocooperação e pelo compartilhamento de informação. No segundo momento, invocamos a ideia de rede, pensada enquanto conjunto interconectado de vias e meios de transporte, equipamentos de comunicação e prestação de serviços. Percebendo, ainda, a rede a partir do seu viés social, compartilhamos do pensamento de Milton Santos (2006) de que as redes são compostas por pessoas, mensagens e valores. Por fim, aproveitando as discussões acerca de Sistemas Memoriais e redes, inserimos um breve histórico sobre a formação da Rede Memorial, um conjunto de princípios que sustentam uma política de preservação e acesso para os acervos memoriais de instituições de vários lugares do Brasil. 


\section{Sistemas memoriais}

De acordo com Aldo Barreto (2005), a liberdade do fluxo de informação e seu compartilhamento amplo e irrestrito é um projeto que remonta ao século XVII. Desde então visava-se erigir uma sociedade integrada por redes de distribuição do saber. Nesse particular, a Enciclopédia representou uma série de esforços empreendidos em conjunto em torno da compreensão semântica e da organização do conhecimento de uma época. Seu intento era facilitar e socializar o acesso à informação a um número de pessoas tão grande quanto possível.

Desde então, a chamada sociedade do conhecimento está sustentada pelo ideal da universalização do acesso ao conhecimento, entendido como o principal recurso econômico. Os séculos se passaram e diante de gerações se descortinaram significativos progressos tecnológicos, ao ponto de nos encontrarmos em plena Era do Acesso. Vivemos uma realidade na qual os mercados, cada vez mais, têm aderido ao sistema de redes; até o conceito de propriedade tem se transformado, já que se tem valorizado mais o consumo do que a posse do produto (RIFKIN, 2005).

Para Manuela Azevedo Pinto e Armando Malheiro da Silva (2005), o desenvolvimento das instituições e organizações depende tanto de uma eficiente utilização do recurso informação quanto da capacidade de armazená-lo e recuperálo. Os desafios que se apresentam às organizações, neste caso, demandam, para além de uma aparelhagem tecnológica, um reequacionamento da estrutura organizacional. Essa quase que transformação necessária se apresenta como:

Resultado inevitável e incontornável da integração das organizações na Sociedade de Informação, na qual a componente da informação e do conhecimento desempenha um papel nuclear em todos os tipos de atividade humana em consequência do desenvolvimento da tecnologia digital, e da Internet em particular, induzindo novas formas de organização da economia e da sociedade, criando um modelo de desenvolvimento social e económico em que a aquisição, o armazenamento, processamento, valorização, transmissão, distribuição e disseminação da informação conducente à criação de conhecimento e à satisfação das necessidades dos cidadãos e das organizações, através das novas tecnologias da informação e comunicação, desempenham um papel central na atividade económica, na criação de riqueza, na definição da qualidade de vida dos cidadãos e das suas práticas culturais. (PINTO; SILVA, 2005, p. 2).

A missão da rede memorial: capital social, sistemas e redes de colaboratividade 
No entendimento de Castells (1999), as culturas se manifestam basicamente através de sua inserção nas organizações - sistemas específicos de meios focados na execução de objetivos específicos - e instituições - organizações investidas de autoridade e capazes de desempenhar atividades específicas em prol da sociedade. Isso porque:

Formas de organização econômica não se desenvolvem em um vácuo social: estão enraizadas em culturas e instituições. Cada sociedade tende a gerar os próprios sistemas organizacionais. Quanto mais historicamente distinta é uma sociedade, mais ela se desenvolve de forma separada das outras e mais específicas são suas formas organizacionais. (CASTELLS, 1999, p. 233).

A partir dessa linha de raciocínio, podemos pensar que um conjunto de instituições e/ou organismos que interagem e trocam experiências, materiais e métodos em torno de um objeto comum, denotam a ideia de sistema. E se tal sistema está ligado à memória e à informação - com base na ideia de que "[...] os sistemas são fontes de informação e a informação é capaz de construir um sistema [...]" (ROBREDO, 2003, p. 110) -, então podemos introduzir em nossas considerações a ideia de sistemas memoriais.

Para Silva e Ribeiro (2002), os chamados sistemas artificiais convencionais implicam a intervenção humana e suas relações organizativas e dinâmicas, dispostas de modo a tecer uma rede. De forma análoga, Pinto e Silva (2005) acrescentam que o elemento caracterizador da Sociedade da Informação é o produto da ação humana e reflexo das condições estruturais - políticas, técnicas, econômicas e culturais - nas quais as ações se desenvolvem a fim de concretizar os diferentes objetivos.

Nessa perspectiva, a informação, enquanto fenômeno e processo, impõe-se às organizações e nas organizações. E nesse contexto, uma organização forte, com um sistema de informação bem estruturado, poderá encontrar na cooperação, na construção de redes de organizações, no uso efetivo do conceito de "rede" a plataforma para responder à economia global, quer a partir da própria capacidade de iniciativa, quer como resposta a incentivos estatais (PINTO; SILVA, 2005).

Da mesma forma, devemos pensar a ideia de Sistema de Informação como o 
fruto da relação transdisciplinar suscitada pela lógica sistêmica. Um sistema de informação, nessa perspectiva, é definido como:

\begin{abstract}
A capacidade de toda e qualquer Organização (baseada ou mediada por estrutura administrativa e funcional ou orgânico-funcional) agir em todos e diversos níveis para atingir, concretizar e rentabilizar objetivos centrais/genéricos e específicos ou ligados à natureza do 'segmento' público-político, político-social e sócio-económico da Organização. (PINTO; SILVA, 2005, p. 7-8).
\end{abstract}

Em conformidade com essa linha de pensamento, o modelo Sistema Memorial sugere a leitura do conjunto de segmentos interoperantes ${ }^{1}$ de missão memorial alocado no universo de arquivos, bibliotecas e museus, bem como outros serviços públicos e privados operantes no resgate, na preservação e no acesso à herança cultural registrada (GALINDO, 2012b).

Enfatizamos, nesse particular, que os sistemas memoriais se apresentam como uma teoria em desenvolvimento que busca a compreensão integrada daqueles equipamentos de missão memorial que atuam a serviço da sociedade. Desse modo:

\footnotetext{
Vê-se que o sistema aqui tratado foge da lógica cartesiana e se apresenta como um organismo aberto e entrópico. $\mathrm{O}$ que sugere ininterruptas transformações e trocas com o meio externo, cuja influência pode até modificar a estrutura do sistema. Desse modo, é apropriado afirmar que o meio e o sistema se complementam em suas distinções. (GOUVEIA JUNIOR; GALINDO, 2012, p. 216).
}

Vale considerar, ainda, que pensar sistemicamente significa defender uma visão não-mecanicista e pós-cartesiana, afastando-se das noções reducionistas, deterministas e analíticas de se pensar o universo-como-máquina. Significa pensar em redes, em teias de interconexões. O universo, então, é percebido como um todo dinâmico, indivisível, cujas partes estão interrelacionadas, enquanto que a ordem, a reversibilidade e o equilíbrio estático também tendem a ser evitadas pelo fato de não corresponderem às realidades das ciências, muito menos às dinâmicas sociais.

Essa tessitura orgânica engendra a perspectiva de que nenhuma sociedade é capaz de sobreviver como sistema de ação se o organismo não se adapta a um meio ecológico, além do que lhe é destinado. Tal concepção pode ser traduzida a partir do 
entendimento de que um organismo que não se reinventa ante a adversidade está fadado ao desaparecimento.

É pertinente anotarmos que a noção de sistema memorial começou a fazer parte da agenda política nacional ao mesmo tempo em que novos marcos conceituais e práticos começavam a ser estabelecidos para a gestão da cultura brasileira, tirandoa das margens políticas governamentais ${ }^{2}$ (GOUVEIA JUNIOR; GALINDO, 2012).

Nesse contexto, tal ideia se soma ao advento do novo paradigma tecnológico anunciado por Castells (1999), pautado no poder das novas tecnologias da informação. Este pensamento vem agindo no sentido de tornar a própria informação o produto do processo produtivo.

\section{Redes de Colaboratividade Informacional}

Entre os muitos significados do termo rede $e^{3}$, advém a ideia de um conjunto interconectado de vias e meios de transporte; de canais de escoamento ou distribuição; de fios ou circuitos entre uma fonte de eletricidade e as unidades de consumo; de meios e equipamentos de comunicação; ou de locais e agentes de prestação de serviços (FERREIRA, 2010).

Essa seria uma noção mecanicista de rede pouco aplicável à ideia que defendemos; uma trama interconectada de inteligências que trabalham nos substratos dos sistemas memoriais, dando-lhes vida. Trata-se, portanto, de uma rede que tem natureza humana. Essa noção aproxima-se mais do conceito defendido por Milton Santos (2006) acerca do viés social - e também político - da rede; necessariamente formada por pessoas, mensagens e valores.

Para Edgar Morin (2007), o homem é um ser biológico e ao mesmo tempo cultural, e que, portanto, vive num universo de linguagem, de ideias e de consciência.

De acordo com Fritjof Capra (2006), as redes são capazes de engendrar uma massa de conhecimento compartilhável que envolve informações, ideias, habilidades, valores e crenças. Essa lógica social de tramas e trocas, evidenciada tanto pela teoria dos sistemas quanto pelo pensamento em rede, guarda estreita 
relação com o universo da Biologia. Um desses conceitos biológicos é o mutualismo; relação entre duas espécies que gera benefícios a ambos os agentes.

Para Bruno Latour (1994), a disposição em rede é uma forma de organização que não é uma prerrogativa humana, tendo em vista que os animais também vivem e demonstram um comportamento interespécies em forma de rede ${ }^{4}$. $\mathrm{O}$ comensalismo e a protocooperação são tratos que podem ser anotados e aplicados nas relações humanas e interinstitucionais. E nesse caso, valem, a título de exemplo, as anotações de Maturana e Varela (1995) em relação aos insetos sociais, aos vertebrados sociais e aos babuínos ${ }^{5}$.

A rede representa, nesse sentido, o fio de Ariadne $^{6}$, que nos conduz em meio ao universo híbrido das trocas sociais - por mais que ainda nos percebamos compartimentados entre a ciência, a filosofia ou a política. E essa trama invisível, naturalmente tributária da interdisciplinaridade, e por isso defensora da supressão de fronteiras, apresenta-se como real, coletiva e discursiva (LATOUR, 1994).

O mesmo Latour (2004) percebe a biblioteca não como uma fortaleza isolada, mas como um nó de uma vasta rede por onde circula a matéria passível de ser transformada em signos. No seu entendimento de rede social, então, há ênfase no processo e não na matéria. E nessa perspectiva, a informação não é um signo, mas uma relação que se estabelece entre dois lugares - centro e periferia ${ }^{7}-$, desde que entre estes circule uma inscrição. Desse modo, tal instituição se apresenta como um receptáculo provisório de onde emanam fluxos e trocas contínuas. Todavia:

[...] as instituições como as bibliotecas, os laboratórios, as coleções não são simples meios que se poderiam dispensar facilmente, sob pretexto de que os fenômenos falariam por si mesmos à simples luz da razão. Adicionamos uns aos outros, eles compõem os fenômenos que só têm existência por esta exposição através das séries de transformações. (LATOUR, 2004, p. 59).

A ideia de capital social vem ao encontro e complementa as noções apresentadas sobre a teoria dos sistemas e pensamento em rede. Embora esse conceito possua diversas significações, derivadas de outras tantas orientações teórico-metodológicas, estamos certos de tratarmos aqui de um conceito relacional, que é norteado a partir do entendimento de capital social como interação que une 
indivíduos em torno de objetivos comuns e evidencia relações de colaboração, reciprocidade e confiança mútua que os torna mais fortes.

Ainda nessa perspectiva, podemos acrescentar que o capital social reside na estrutura das suas relações. É, então, a partir do relacionamento com o outro que o indivíduo obtém capital social. Ademais, estes novos tempos demandam a formação de parcerias e colaborações com base na percepção de que, através da integração de instituições de missão memorial, será possível a prestação de um serviço abrangente e de qualidade. Essa integração é tributária, contudo, da superação dos modos tradicionais de delimitação territorial (MARQUES, 2010).

A força das relações reticulares, por sua vez, depende de que cada ponto da rede se apoie nos outros pontos da rede, "[...] e é porque a rede local adiciona, junta essas fraquezas umas com as outras, que ela engendra força". (CALLON, 2004, p. 77). Se pensarmos essas teias de relacionamento e troca de informação em um nível maior, isto é, entre comunidades e/ou instituições, o capital social é capaz de conceder benefícios à sociedade, bem como potencializar a aprendizagem, a mobilidade social e o desenvolvimento econômico, desde que exista um conjunto de instituições e sujeitos comprometidos com essa finalidade.

As argumentações até agora levantadas dão conta de um corpo teórico dos sistemas memoriais. E este se apresenta como uma apreensão lógica a partir da teoria dos sistemas, que dá visibilidade a um conjunto interconectado de instituições que operam em sistema. Em suma, é uma abordagem teórica. A rede memorial, por sua vez, que passamos a abordar, é uma instância pragmática dessa visão teórica, que, ao mesmo tempo, é o laboratório e o experimento onde testamos e avaliamos as construções do sistema memorial.

\section{A tessitura da rede memorial: aproximações}

Podemos citar como exemplo pela busca da construção de um sistema memorial a disposição de vários representantes de instituições memoriais do Brasil no sentido de estabelecer uma rede. Trata-se da Rede Nacional das Instituições Comprometidas com Políticas e Digitalização dos Acervos Memoriais do Brasil. A chamada Rede 
Memorial se baseia em princípios que sustentam uma política de preservação e acesso aos acervos memoriais, em prol de um espaço colaborativo de trabalho.

No início de 2009, o Museu da Cidade do Recife, a Biblioteca Pública de Pernambuco, o Arquivo Público Estadual Jordão Emerenciano e o Laboratório Liber da Universidade Federal de Pernambuco (UFPE), de comum acordo, iniciaram diálogos sobre problemas comuns em locais de memória. Seus representantes compreenderam que poderiam somar pela semelhança e não separar pela diferença. Essa rede local objetivava a promoção da cooperação interinstitucional mediante a realização de programas estratégicos de promoção, preservação e acesso ao patrimônio memorial e à informação de natureza histórica, custodiados por instituições de missão memorial de Pernambuco (GALINDO, 2010).

Entre os dias 13 e 15 de setembro de 2011, aconteceu, no Recife Pernambuco, a Conference on Technology Culture and Memory - CTCM. O evento contou com a participação de palestrantes nacionais e internacionais, especialistas em gestão do patrimônio cultural e pesquisadores. Seus objetivos eram: refletir sobre o papel das instituições de patrimônio cultural nas sociedades em rede; debater o impacto da digitalização sobre as organizações; e trocar impressões acerca das tendências da digitalização nas instituições públicas e privadas e da influência das novas mídias na formatação do conhecimento (CARTA DO RECIFE, 2011).

Durante o evento, realizou-se como atividade paralela a Primeira Reunião de Gestores de Arquivos Públicos e Centros de Documentação dos Estados Brasileiros, com representantes de 30 instituições públicas e privadas envolvidas com projetos de digitalização de acervos para discutir caminhos práticos na contribuição dos processos em curso de valorização da cultura brasileira. Os representantes decidiram estabelecer uma rede nacional, denominada Rede Memorial, tendo por base uma carta de princípios $^{8}$ para sustentar uma política de digitalização de acervos memoriais e de procedimentos para a conformação de um espaço colaborativo de trabalho.

Foi criado um Comitê Gestor da Rede Memorial com objetivos de implantar uma plataforma colaborativa, criar grupos de trabalho, preparar um plano de atividades para os anos 2011 e 2012, buscar permanente diálogo com a Secretaria 
de Políticas Culturais do Ministério da Cultura, divulgar a formação da Rede e preparar uma nova reunião deste Fórum para maio de 2012 (CARTA DO RECIFE, 2011).

Etapa importante desse processo foram os esforços empreendidos em torno da definição de diretrizes para uma política pública de apoio à produção de conteúdos digitais. No segundo semestre de 2007, ocorreram dois encontros promovidos pelo Comitê Gestor da Internet no Brasil, onde diversas entidades públicas e privadas assinaram um memorando de intenções. Através deste documento, tais instituições se comprometiam a, utilizando-se das novas tecnologias digitais, revalorizar os seus acervos e se tornar grandes produtoras de conteúdo indispensável às culturas brasileiras e essenciais à consolidação de identidades neste novo século (CARTA DO RECIFE, 2011).

Em abril de 2010, durante o Simpósio Internacional de Políticas Públicas para Acervos Digitais, realizado em São Paulo, discutiram-se as políticas públicas de digitalização de acervos e a formulação de um modelo sustentável de preservação e acesso universal do patrimônio cultural brasileiro. Quase que simultaneamente a esse evento, o Conselho Nacional dos Arquivos estabeleceu as diretrizes gerais para o processo de digitalização dos acervos - ferramenta indispensável ao seu acesso, disseminação e preservação, já que se restringe à utilização dos documentos originais (CARTA DO RECIFE, 2011).

Vale lembrar, nesse contexto, que o Plano Nacional de Cultura estabelece o direito à informação, à comunicação, à crítica cultural e à memória, promovidos por meio dos museus, arquivos e coleções; determina a articulação de políticas públicas de cultura e a promoção à organização de redes e consórcios para a sua implementação de forma integrada com as políticas públicas de educação, comunicação, ciência e tecnologia; demanda ampla publicidade e transparência para as informações declaradas e sistematizadas, preferencialmente em meios digitais, atualizados tecnologicamente e disponíveis na rede mundial de computadores; e ainda determina a necessidade de implementação de uma política nacional de digitalização e atualização tecnológica de laboratórios de produção, conservação, restauro e reprodução de obras artísticas, documentos e acervos culturais mantidos 
em museus, bibliotecas e arquivos, integrando seus bancos de conteúdos e recursos tecnológicos (BRASIL, 2010).

Nesse particular, devemos anotar a realização das conferências de cultura ocorridas em nível nacional. A primeira delas, realizada em 2005, teve como tema central a interação do Estado e da sociedade na construção da política pública de cultura. Em 2010, a segunda edição do evento, entre outras deliberações, tratou de discutir a criação de dispositivos de atualização da lei de direitos autorais em consonância com os novos modos de fruição e produção cultural que têm surgido a partir das novas tecnologias, garantindo o livre acesso a bens culturais compartilhados sem fins econômicos desde que não cause prejuízos aos titulares das obras.

A capital federal abrigou, em novembro de 2013, a $3^{\text {a }}$ Conferência Nacional de Cultura, cujo tema escolhido foi Uma política de Estado para a cultura: desafios do Sistema Nacional de Cultura. Nessa ocasião, reuniram-se representantes da sociedade civil e membros do governo. Foram discutidos também a produção simbólica e a diversidade cultural, a cidadania e os direitos culturais e o desenvolvimento econômico.

Essas políticas para a produção e disseminação de cultura, memória e informação, tal como têm se apresentado, devem contar, ainda, com a expertise dos agentes envolvidos com os programas de digitalização de seus acervos. Nesse particular, é fundamental que sejam preestabelecidos padrões de procedimento a serem adotados pelos membros da rede. Rede esta que ganha mais vigor a partir da colaboração de um tão grande quanto impreciso número de atores individuais ou coletivos. Atenta a essa intensa atividade, a Rede Memorial tem-se dedicado à tarefa de impulsionar esse esforço de cooperação entre instituições e projetos (CARTA DO RECIFE, 2011).

Conforme já pontuamos, a reunião na qual foi elaborada a Carta do Recife tinha por principal objetivo a discussão de caminhos práticos para contribuir com os processos em curso de valorização da cultura brasileira. Para tanto, os envolvidos na confecção dessa rede estavam convencidos da importância da adesão a seis princípios básicos ${ }^{9}$ para que se defina uma política de digitalização dos acervos 
memoriais, em tempo: o compromisso com o acesso aberto, público e gratuito; o compromisso com o compartilhamento das informações e da tecnologia; o compromisso com a acessibilidade; a criação de padrões de captura e de tratamento de imagens; a definição de padrões de metadados e de arquitetura da informação dos repositórios digitais; e a criação de padrões e normas de preservação digital de longo prazo, que se harmonizam, inclusive, com os padrões universais estabelecidos para documentação digital adotados pela Comunidade Européia ${ }^{10}$.

$\mathrm{O}$ que ficou claro neste congresso foi a necessidade de se somarem esforços para discutir políticas públicas com objetivo de orientar as iniciativas de patrocinadores, agências financiadoras e fundos que oferecem recursos para a reprodução digital dos acervos (SOARES, 2011).

Entre os dias 21 e 22 de junho de 2012, aconteceu o II Fórum da Rede Memorial na Cinemateca Brasileira em São Paulo, que contou com a presença da Coordenação da Cultura Digital do Ministério da Cultura. O Comitê Gestor apresentou uma proposta para o Projeto Documenta e o Projeto Memorial Digital. Nessa ocasião, foram divididos os grupos para dar início aos trabalhos: 1. Digitalização e Preservação Digital; 2. Metadados e Arquitetura da Informação de Repositórios da Rede; 3. Diagnóstico das Instituições e Estruturação da Rede (CARTA DO RECIFE, 2014).

A Rede Memorial de Pernambuco continuou suas atividades e hoje conta com a participação do Museu do Estado de Pernambuco (MEPE), Memorial da Justiça, Instituto Ricardo Brennand (Instituto RB), Companhia Editora de Pernambuco (CEPE), da Fundação Joaquim Nabuco (FUNDAJ), da Fundação do Patrimônio Histórico e Artístico de Pernambuco (FUNDARPE), da Superintendência de Desenvolvimento do Nordeste (SUDENE) e do Paço do Frevo.

No tocante à entrada da SUDENE na Rede Memorial e sua parceria com a UFPE, destacamos a toma de consciência, em 2012, da necessidade de se digitalizar as atas de reuniões produzidas, entre 1959 e o ano 2000, pelo Conselho Deliberativo $^{11}$ da instituição. A iniciativa implementada ${ }^{12}$ não se limitava a conservar documentos em novos suportes, mas a viabilizar o seu acesso. O que revela a tendência a se afastar do custodialismo ao mesmo tempo em que se efetiva 
o valor social de uma organização deste porte e importância histórica para a sociedade com vistas à (re)construção de sua identidade e memória, mediante discussões e formulações de novos conhecimentos, de políticas públicas e fixação de diretrizes de desenvolvimento social.

No bojo deste processo de consolidação da Rede Memorial, a Secretaria de Gestão da Informação e Comunicação (SEGIC) e Biblioteca Central (BC) da UFPE criaram o Memorial Denis Bernardes ${ }^{13}$. O espaço, aberto em 2013, e que se destina a preservar a memória institucional da UFPE, abriga em seu acervo discos de vinil, fitas de programas da TV Universitária, bem como arquiva as coleções de Paulo Freire, e os acervos Acervo João Alfredo, Marcos Freire e Padre Daniel Lima.

A ênfase de suas ações está na guarda e digitalização de documentos, que contribuem no sentido de revelar um pouco da cultura regional e nacional, fundamental para qualquer pesquisador que se dedique à referida temática. A parceria entre o Memorial e o Laboratório de Tecnologia da Informação da UFPE, através de investimentos em servidores web, garante o acesso a arquivos digitalizados.

Mais um fruto de um importante convênio de cooperação técnica firmado entre duas instituições de missão memorial de nosso estado foi o Arquivo Público Estadual Jordão Emereciano ${ }^{14}$ (APEJE) e a CEPE. As duas instituições dedicaramse à digitalização de Jornais dos séculos XIX e XX e do Jornal Diário da Manhã (1927 a 1985), e, através desse trabalho em conjunto de preservação e disseminação de informação, colocaram a tecnologia a serviço da memória pernambucana.

Ainda sobre o APEJE, devemos enfatizar que este teve cinco projetos aprovados pelos editais Multiusuário da Fundação de Amparo à Ciência e Tecnologia do Estado de Pernambuco (FACEPE) ${ }^{15}$ de 2010 e 2012, totalizando um investimento de mais de um milhão de reais. Em tempo, em 2010, o APEJE recebeu financiamentos para os projetos de Preservação do Acervo Documental da Casa de Detenção do Recife - Prontuários; Catalogação do Acervo Iconográfico do APEJE; e Retratos da Cultura Política - Ofícios do Governo. Em 2012, esta mesma instituição conseguiu subsídios para o projeto de Catalogação do Acervo do Instituto de Medicina Legal Antônio Percivo Cunha (1925-1979). Em todos os 
casos, como se pode perceber, as ações envolveram tratamento, organização, digitalização e disponibilização da informação ao franco acesso do usuário.

\section{Considerações finais}

Tendo discorrido acerca da ideia de Sistemas Memoriais e como esta tem se apresentado de modo a priorizar a protocooperação e o compartilhamento de informação e de boas práticas entre instituições envolvidas, ao mesmo tempo em que se defende a concepção reticular dessa categoria de trabalho, que envolve pessoas, mensagens e valores, devemos ainda anotar algumas ressalvas importantes.

Conscientes de que o ato de compartilhar, aparentemente elementar, representa um exercício delicado para muitas organizações que percebem o controle da informação como sinônimo de poder, as ações pensadas e realizadas sob a lógica da Rede Memorial tendem a se aproximar das relações ecológicas. Estas se fazem importantes em virtude da percepção de um novo paradigma, que engendra uma visão holística do mundo, e o apreende não como a reunião das partes dissociadas, mas como um todo integrado. Começamos, então, a perceber que o sucesso na gestão partilhada da memória depende da combinação entre mudanças tecnológicas e comportamentais e do intercâmbio e socialização de experiências. Esse conjunto de princípios sustenta a intenção coletiva de se construir uma política de preservação e acesso para os acervos memoriais de instituições, não apenas de Pernambuco, mas de vários lugares do Brasil.

Apesar dos esforços de articulação interinstitucional, ainda não se atingiu um modelo de política de memória para Pernambuco. Com essa finalidade, tem-se iniciado negociações entre instituições desejosas de se envolverem nessa tarefa. Nesse sentido, é fundamental que se discutam políticas públicas específicas para o patrimônio e a memória nas esferas municipal e estadual.

Um importante capítulo desse conjunto de iniciativas aconteceu no dia 20 de maio de 2014, quando ocorreu a audiência pública sobre o Projeto de Lei Ordinária n $1932 / 2014$, que cria o Conselho Estadual de Política Cultural e o Conselho Estadual de Preservação do Patrimônio Cultural no âmbito do Estado de 
Pernambuco (PERNAMBUCO, 2014). O que nos faz pensar que outras iniciativas devem se desenvolver nessa perspectiva, de modo a intensificar as nossas conquistas em prol da preservação e compartilhamento de memória. Essa política deve ser construída não só mediante profunda reflexão e planejamento, mas também através da experiência acumulada pelos atores efetivamente envolvidos com a digitalização dos seus acervos. Nesse particular, a fixação dos padrões e procedimentos deve, necessariamente, estar atrelada ao cotidiano da produção desta dimensão da cultura digital, conforme pontua a Carta do Recife $2.0^{16}$.

As instituições ligadas à cultura, à memória e ao patrimônio responsáveis pela preservação e pelo acesso de acervos que conformam e permitem a existência da memória nacional têm desenvolvido diversas iniciativas de reprodução e publicação na Internet de seus acervos. Cabe à Rede Memorial impulsionar um esforço de cooperação e de genuína solidariedade entre instituições e projetos. O que caracteriza um movimento essencial para a cultura brasileira no século XXI.

\section{Referências}

BARRETO, Aldo de Albuquerque. As tecnoutopias do saber: redes interligando o conhecimento. Datagramazero: Revista de Ciência da Informação. Rio de Janeiro, v. 6, n. 6, dez. 2005, p.1-13. Disponível em:

<http://www.dgz.org.br/dez05/Art_01.htm>. Acesso em: 6 jun. 2014.

BRASIL. Lei n. 12343, de 2 de dezembro de 2010. Disponível em:

<http://www.planalto.gov.br/ccivil_03/_ato2007-2010/2010/lei/112343.htm>. Acesso em: 8 maio 2014.

CALLON, Michael. Por uma nova abordagem da ciência, da inovação e do mercado: o papel das redes sócio-técnicas. In: PARENTE, André (Org.). Tramas da rede: novas dimensões filosóficas, estéticas e políticas da comunicação. Porto Alegre: Sulina, 2004. p. 64-79.

CAPRA, Fritjof. A teia da vida: uma nova compreensão científica dos sistemas vivos. São Paulo: Cultrix, 2006.

CARTA DO RECIFE 2.0. Disponível em: <http://redememorialpernambuco.blogspot.com.br/p/carta-do-recife.html >. Acesso em 9 jun. 2014.

A missão da rede memorial: capital social, sistemas e redes de colaboratividade 
CARTA DO RECIFE. Rede Memorial - Rede Nacional das Instituições Comprometidas com Políticas de Digitalização dos Acervos Memoriais do Brasil. Recife, 11 set. 2011, p. 1-7. Disponível em: <http://www.academiapeciencias.org/cartas/CARTA\%20DO\%20RECIFE\%202011. pdf>. Acesso em: 3 abr. 2014.

CASTELLS, Manuel. A sociedade em rede. 6. ed. São Paulo: Paz e Terra, 1999.

FERREIRA, Aurélio Buarque de Holanda. Miniaurélio: o dicionário da língua portuguesa. 8. ed. Curitiba: Positivo, 2010.

GALINDO, Marcos. Conhecimento: custódia e acesso. In: FERREIRA, Sueli Maria Soares Pinto; TARGINO, Maria das Graças (Org.). Conhecimento: custódia e acesso. 2. ed. São Paulo: SIBiUSP, 2012a.

GALINDO, Marcos. O dilema de Pharmacon. Ciência da Informação, Brasília, v. 41, n. 1, p.36-50, jan./abr. 2012b. Disponível em:

<http://revista.ibict.br/ciinf/index.php/ciinf/article/view/2111>. Acesso em: 16 jul. 2014.

GALINDO, Marcos. Tecnologia \& Memória. Revista do Instituto de Estudos Brasileiros, São Paulo, n. 50, p. 179-190, set./mar. 2010. Disponível em: 〈http://www.revistas.usp.br/rieb/article/view/34655/37393>. Acesso em: 20 maio 2014.

GALINDO, Marcos; MIRANDA, Márjory Oliveira; BORBA, Vildeane. A memória e os sistemas memoriais. In: ENCONTRO NACIONAL DE PESQUISA EM CIÊNCIA DA INFORMAÇÃO, 12., 2011, Brasília. Anais... Brasília, 2011, p.33283339.

GOUVEIA JUNIOR, Mário. A economia da memória: um estudo do sistema pernambucano. 2012. 208 f. Dissertação (Mestrado em Ciência da Informação) Programa de Pós-graduação em Ciência da Informação, Universidade Federal de Pernambuco, Recife, 2012.

GOUVEIA JUNIOR, Mário. Segurança ou Liberdade? O pensamento de Bauman e as relações de mediação nos Sistemas de Informação. Prisma.Com, Aveiro, v.24, p. 3-16, 2014. Disponível em:

〈http://revistas.ua.pt/index.php/prismacom/article/view/2934>. Acesso em: $11 \mathrm{dez}$ 2014.

GOUVEIA JUNIOR, Mário; GALINDO, Marcos. Sistemas memoriais como disseminadores de informação. Transinformação, Campinas, v. 24, n. 3, p. 207217, set/dez. 2012. Disponível em: <http://periodicos.puccampinas.edu.br/seer/index.php/transinfo/article/view/1203>. Acesso em: 5 jun. 2014. 
LATOUR, Bruno. Redes que a razão desconhece: laboratórios, bibliotecas, coleções. In: PARENTE, André (Org.). Tramas da rede: novas dimensões filosóficas, estéticas e políticas da comunicação. Porto Alegre: Sulina, 2004. p. 3963.

LATOUR, Bruno. Jamais fomos modernos: ensaio de Antropologia Simétrica. Rio de Janeiro: Editora 34, 1994.

MARQUES, Isabel da Costa. O museu como sistema de informação. $170 \mathrm{f}$. Dissertações (Mestrado em Museologia) - Programa de Pós-graduação em em Museologia, Universidade do Porto. Porto, 2010. Disponível em: < http://repositorioaberto.up.pt/bitstream/10216/55282/2/TESEMESISABELMARQUES000124492.pd f>. Acesso em: 29 maio 2014.

MATURANA, Humberto; VARELA, Francisco. A árvore do conhecimento: as bases biológicas do entendimento humano. Campinas: Workshopsy, 1995.

MORIN, Edgar. Introdução ao pensamento complexo. 3. ed. Porto Alegre: Sulina, 2007.

MUSSO, Pierre. A filosofia da rede. In: PARENTE, André (Org.). Tramas da rede: novas dimensões filosóficas, estéticas e políticas da comunicação. Porto Alegre: Sulina, 2004. p. 17-38.

NORA, Pierre. Entre memória e história: a problemática dos lugares. Projeto História: Revista do Programa de Estudos Pós-Graduados em História e do Departamento de História da PUC-SP, São Paulo, n. 10, p. 7-28, 1993. Disponível em: 〈http://www.pucsp.br/projetohistoria/downloads/revista/PHistoria10.pdf〉. Acesso em: 16 maio 2014.

PERNAMBUCO. Projeto de Lei Ordinária No 1932/2014. Disponível em: $<$ http://www.alepe.pe.gov.br/paginas/verprojeto.php?paginapai=3597\&numero=193 2/2014\&docid=35CB57645D52210503257CB00034ECFF>. Acesso em:10 jun. 2014.

PINTO, Manuela; SILVA, Armando Malheiro da. Um modelo sistémico e integral de gestão da informação nas organizações. 2005. In: CONGRESSO INTERNACIONAL DE GESTÃO DA TECNOLOGIA E SISTEMAS DE INFORMAÇÃO, 2., 2005, São Paulo. Anais... São Paulo, 2005. Disponível em: <http://ler.letras.up.pt/uploads/ficheiros/3085.pdf>. Acesso em: 6 maio 2014.

RIFKIN, Jeremy. A era do acesso: transição de mercados convencionais para networks e o nascimento de uma nova economia. 2. ed. São Paulo: Makron Books, 2005. 
ROBREDO, Jaime. Da ciência da informação revisitada aos sistemas humanos de informação. Brasília: Thesaurus; SSRR Informações, 2003.

SANTOS, Milton. Por uma geografia das redes. In: . A natureza do espaço: técnica, razão e emoção. 4. ed. São Paulo: Editora da USP, 2006. p. 176-189. Disponível em:

<http://www.geociencia.xpg.com.br/dwd/Milton_Santos_A_Natureza_do_Espaco.p df>. Acesso em: 10 jun. 2014.

SILVA, Armando Malheiro da; RIBEIRO, Fernanda. Paradigmas, serviços e mediações em Ciência da Informação. Recife: Néctar, 2011.

SILVA, Armando Malheiro da; RIBEIRO, Fernanda. Das "ciências" documentais à ciência da informação: ensaio epistemológico para um novo modelo curricular. Porto: Edições Afrontamento, 2002.

SOARES, Sandra Maria Verissimo. O microfilme e o digital: as duas faces da preservação. 2011. 163 f. Dissertação (Mestrado em Ciência da Informação) Programa de Pós-graduação em Ciência da Informação, Universidade Federal de Pernambuco, 2011.

THE EUROPEAN LIBRARY. About the European Library services for libraries. Disponível em: 〈http://www.theeuropeanlibrary.org/>. Acesso em: 12 jul. 2014.

\title{
The mission of the Rede Memorial: social capital, systems and collaborative networks
}

\begin{abstract}
This study discusses the importance of the formation and consolidation of a network of institutions of memorial mission for the preservation of information, its dissemination and its frank and unrestricted access. Our considerations illustrate the idea of memorial system, designed as a category of work that values the protocooperation and the sharing of information. We contemplate the prospect that, working together, institutions can contribute more effectively regarding the sharing of information contents. Likewise, we contemplate the formation of the Rede Memorial (Memorial Network) - the search for a national integration which is based on a letter of principles to support a policy of digitizing the collections of memorials and procedures to form a collaborative work space.
\end{abstract}

Keywords: Memorial systems. Memorial network. Collaborativity. Access to information. 
${ }^{1}$ A interoperabilidade, aqui apresentada, define-se como aquela habilidade desenvolvida por dois ou mais sistemas no sentido de compartilhar dados e informações de modo coerente e eficiente, buscando a maximização dos resultados esperados, mesmo atuando em diferentes ambientes.

${ }^{2}$ A confecção da Carta do Recife e a própria realização da Conference on Technology Culture and Memory CTCM são exemplos desse conjunto de ações de relevância para o fortalecimento da compreensão e da aplicabilidade dos conceitos de rede de compartilhamento de informação e de sistemas memoriais tratados neste artigo.

${ }^{3}$ Uma ferramenta de análise; um operador de leitura; um modo de raciocínio, uma tecnologia do espírito; uma matriz técnica; uma metáfora; um sólido cristal; um sistema de circulação de fluidos; um diagrama; uma árvore; um labirinto (MUSSO, 2004).

${ }^{4}$ De forma mais ampla, possuir uma organização não é uma característica exclusiva dos seres vivos, mas de todas as coisas que podemos analisar enquanto sistema (MATURANA; VARELA, 1995).

${ }^{5}$ Em relação ao primeiro grupo, representado por formigas, cupins, vespas e abelhas, estes denotam forte interação de grupo a partir de características inatas, que determinam sua função e obrigações para com a sua comunidade. No segundo caso, animais distintos cumprem papeis da mesma forma distintos, o que lhes permite a dedicação a atividades, em benefício do grupo, que lhes seriam impossíveis se estivessem sozinhos. No terceiro caso, cada indivíduo está continuamente ajustando sua posição na rede de interações do grupo segundo sua própria dinâmica (MATURANA; VARELA, 1995).

${ }^{6}$ A partir de suas configurações, a rede se presta a orientar o nosso por onde ir para chegar onde se quer.

${ }^{7}$ Vale a ressalva, anotada pelo próprio Latour (2004), de que os fenômenos não se situam nem no exterior nem no interior das redes. Eles residem numa certa maneira de se deslocar que otimiza a manutenção das relações constantes, apesar do transporte e da diversidade dos observadores.

${ }^{8}$ Essa carta nacional foi criada com base nos princípios de criação da Rede Memorial de Pernambuco.

${ }^{9}$ Ver Carta do Recife (2011).

${ }^{10}$ Nesse sentido, devemos ressaltar a emergência da The European Library. Trata-se de uma organização chamada superfície operacional que tem por objetivo agregar todo o conteúdo digitalizado da herança cultural europeia: livros, pinturas, filmes, objetos de museu, arquivos audiovisuais e documentos de arquivo digitalizados. Por meio desta iniciativa, desde 2005, têm sido propiciados aos usuários acessos multilinguísticos comuns a diferentes padrões de herança cultural, da Pré-história à atualidade, distribuídos digitalmente. Os objetos digitais localizáveis a partir da Europeana não são armazenados em um computador central, mas permanecem com a instituição cultural e estão hospedados em suas redes. Desse modo, abrigam-se os metadados de cada conteúdo em um padrão comum, e o pesquisador é direcionado para o site original, caso deseje acessar o conteúdo completo. (THE EUROPEAN LIBRARY, 2014).

${ }^{11}$ Composto por governadores, ministros, técnicos, representantes das classes trabalhadora e empresarial, e, nos primeiros anos, presidido pelo Presidente da República.

12 O Projeto de Preservação e Disponibilização do Acervo do Conselho Deliberativo da SUDENE (PROCONDEL) tem como metas: digitalização, edição e organização da informação do acervo textual; digitalização do acervo sonoro; identificação e digitalização do acervo iconográfico; pesquisa e elaboração de banco de dados de notícias publicadas em jornais; coleta de depoimentos de ex-conselheiros, ex-servidores e ex-colaboradores; produção de documentário; produção de um site; seminários, debates e publicações de livros. O acervo textual do período de 1959 a 1970 já está disponível no site www.sudene.procondel.org.

${ }^{13} \mathrm{O}$ nome do Memorial é uma homenagem ao professor Denis Bernardes, que atuou nos Departamentos de Economia e de Serviço Social e se destacou pelo interesse na guarda de documentos da UFPE, bem como nas relações entre memória, informação e sociedade.

${ }^{14}$ Criado pelo Decreto Estadual n. 1265 de 04 de dezembro de 1945, o APEJE apresenta-se à sociedade, desde então, como um dos principais guardiões da memória histórico-administrativa deste estado, tendo em vista que abriga o terceiro maior conjunto documental público do país - composto por documentos textuais, impressos, iconográficos, bibliográficos e folhetos raros, plantas arquitetônicas e periódicos - e recebe desde estudantes até pesquisadores locais, nacionais e estrangeiros.

15 A FACEPE, no âmbito de sua missão de promover o desenvolvimento científico e tecnológico de Pernambuco, desde 2008, lança, a cada dois anos, um edital de Apoio à Disponibilização para a Pesquisa de Laboratórios Multiusuários e de Acervos de Interesse Científico - Multiusuários. Esse edital tem por objetivo o incentivo e o apoio a projetos de implantação, recuperação, conservação e disponibilização de laboratórios multiusuários ou de acervos de interesse científico. Desse modo, visa-se a ampliação de sua disponibilidade e acessibilidade por pesquisadores em geral, bem como a maximização dos benefícios dessas estruturas, equipamentos e acervos para a geração de conhecimento no estado de Pernambuco.

${ }^{16}$ Vide Carta do Recife 2.0 (2014).

Recebido: 05/09/2014

Aceito: 18/12/2014

A missão da rede memorial: capital social, sistemas e redes de colaboratividade 